\title{
Triterpenoid from Styrax japonica SIEB. et Zucc, and Its Effects on the Expression of Matrix Metalloproteinases-1 and Type 1 Procollagen Caused by Ultraviolet Irradiated Cultured Primary Human Skin Fibroblasts
}

\author{
Hyung-In Moon, ${ }^{*, a}$ Mi-Ran KIM, ${ }^{b}$ Eun-Ran Woo, ${ }^{b}$ and Jin Ho ChunG ${ }^{*, a}$ \\ ${ }^{a}$ Department of Dermatology, Seoul National University College of Medicine and Institute of Dermatological Science, \\ Seoul National University; Seoul, 110-744, Korea: and ${ }^{b}$ College of Pharmacy, Chosun University; Gwangju 501-759, \\ Korea. Received May 10, 2005; accepted July 7, 2005
}

\begin{abstract}
Long term and repeated exposure of ultraviolet light on the skin often induces chronic skin diseases such as skin cancer as well as photoaging, and the mechanisms of these skin damages are closely associated with up-regulation of matrix metalloproteinase's (MMPs) activities. The methylene chloride soluble fraction of methanol extract from the stems of Styrax japonica. (Styracaceae) showed significant MMP-1 inhibition in primary human skin fibroblasts cause by ultraviolet irradiation. Four triterpenoids were isolated by column chromatography. Among them, Erythrodiol-3-acetate reduced of MMP-1 and induced of type 1 procollagen at the protein levels in a dose-dependent manner.
\end{abstract}

Key words Styrax japonica; triterpenoids; MMP-1 inhibitor; ultraviolet

The skin aging process can be divided into intrinsic aging and photoaging. Damage to human skin due to repeated exposure to Ultraviolet (UV) radiation (photoaging) and damage occurring as a result of the passage of time (intrinsic aging) are considered to be distinct entities rather than similar skin aging processes. Photoaging of skin is caused by genetically determined or intrinsic processes superimposed upon the degenerative changes due to solar radiation. ${ }^{1)}$ Alterations and deficiencies of collagen, the major structural component of skin, have been suggested to be a cause of the skin wrinkling observed in photoaged and naturally aged skin., ${ }^{2,3)}$ The dermis contains predominantly type I and type III collagen, elastin, proteoglycans, and fibronectin. Since collagen fibrils and elastin are responsible for the strength and resiliency of skin, their disarrangement during photoaging causes the skin to appear aged. Recently, it was suggested that excessive matrix degradation by UV-induced MMP-1 secreted by various cells, including, keratinocytes, fibroblasts, and inflammatory cells, contributes substantially to the connective tissue damage that occurs during photoaging. ${ }^{4-6)}$ The expression of matrix metalloproteinase's (MMPs) proteins in the dermis of sun-exposed and sun-protected skin of elderly subjects is known to differ. ${ }^{5}$ Photodamaged skin of the elderly shows higher MMP-1 protein expression, than the intrinsically aged skin in the same individual. ${ }^{5)}$ Thus, this resulting higher expression of MMP-1 in photoaged skin may cause severe collagen deficiency and wrinkling. MMPs are a family of zinc-dependent endoproteinases that play pivotal roles in the dynamic remodeling of extracellular matrix. Based on substrate preference and structural homology, MMPs are sub-classified into functional groups: collagenases, gelatinases, stromelysins, matrilysins, membrane typeMMPs (MT-MMPs) and other non-classified MMPs. ${ }^{7)}$ MMPs are frequently overexpressed by the various extracellular stimuli including growth factors, cytokines, tumor promoters, and UV, and this increase in MMP-related activities may be involved in the pathogenesis of diseases such as cancer and inflammation as well as in physiologic processes. ${ }^{78}$ It has been also reported that up-regulation of some MMPs is responsible for the enhanced degradation of dermal collagen during chronological and UV-induced skin aging. ${ }^{4}$ With increasing age, collagen synthesis becomes lower and MMP-1 levels become higher in sun-protected human skin in vivo. ${ }^{3)}$ Therefore, the regulation of MMP activity might be a potential strategy for prevention and/or treatment of UV-induced skin damage. Styrax japonica SIEB. et Zucc. is a member of the Styracaceae family, which is a shrub found in Central America, Mexico, and the Mediterranean region, including West, and South Anatolia. ${ }^{9)}$ The resin from this species has been used in traditional medicine to treat inflammatory diseases ${ }^{10)}$ and was also used by Romans, Egyptians, Phoenicians, and Ionians as both incense, and a medicine. ${ }^{11)}$ An earlier investigation on the chemical constituents from the seeds or leaves of the Styrax species revealed them to be a rich source of benzofurans, ${ }^{12)}$ benzofuran esters, ${ }^{13)}$ benzofuran glycosides, ${ }^{14)}$ and sapogenins. ${ }^{15)}$ In an ongoing investigation into biologically active compounds from natural products, a methylene chloride soluble fraction of $S$. japonica showed significant MMP-1 expression inhibition in vitro. In this paper, we report a compound from the stems of $S$. japonica which inhibit MMP-1 expression and increased the type I procollagen expression in cultured primary human skin fibroblasts cause by UV-irradiation.

\section{MATERIALS AND METHODS}

Isolated Compounds from Styrax japonica The airdried stem bark of S. japonica $(654 \mathrm{~g})$ was cut and extracted with methanol for $4 \mathrm{~h}(\times 3)$ at $70^{\circ} \mathrm{C}$. The methanol extract $(120.3 \mathrm{~g})$ was suspended in water and then partitioned by methylene chloride, ethyl acetate, and $n$-butanol in turn. The methylene chloride fraction $(2 \mathrm{~g})$ was subjected to column chromatography over a silica gel $(210 \mathrm{~g}, 3.8 \times 68 \mathrm{~cm})$ eluting with $n$-hexane:acetone $(100: 1 \rightarrow 2.5: 1, \mathrm{v} / \mathrm{v})$ and $\mathrm{CH}_{2} \mathrm{Cl}_{2}: \mathrm{MeOH}(50: 1 \rightarrow 1: 1, \mathrm{v} / \mathrm{v})$ gradient system. Fractions were combined based on their TLC pattern to yield subfraction designated as $\mathrm{C} 1-\mathrm{C} 7$. Subfraction $\mathrm{C} 1(350 \mathrm{mg}), \mathrm{C} 2$ $(180 \mathrm{mg})$, and C3 $(230 \mathrm{mg})$ were recrystallized from $n$ - 
hexane to afford oleanolic aldehyde acetate (1: $150 \mathrm{mg}){ }^{12)}$ erythrodiol-3-acetate (2: $80 \mathrm{mg}){ }^{16)}$ and euphorginol (3: $\left.100 \mathrm{mg}) .{ }^{17}\right)$ Subfraction C4 (190 mg) was further purified by column chromatography over a silica gel $(135 \mathrm{~g}, 2.3 \times 55 \mathrm{~cm})$ eluting with $n$-hexane-acetone $(10: 1, \mathrm{v} / \mathrm{v})$ isocratic system to afford seven subfraction $(\mathrm{C} 4.1-\mathrm{C} 4.7)$. Among these subfractions, C4.1 (71.7 $\mathrm{mg})$ and C4.2 (52.7 $\mathrm{mg})$ were combined and repeated column chromatography on Sephadex LH-20 $\left(50 \mathrm{~g}, 1.8 \times 45 \mathrm{~cm} ; \mathrm{MeOH}-\mathrm{H}_{2} \mathrm{O}=83: 17, \mathrm{v} / \mathrm{v}\right)$ and silica gel $(100 \mathrm{~g}, 1.8 \times 45 \mathrm{~cm} ; n$-hexane $:$ acetone $=25: 1, \mathrm{v} / \mathrm{v})$ to give anhydrosophoradiol-3-acetate $(4: 55 \mathrm{mg}),{ }^{18)}$ respectively. ${ }^{19)}$ Compound was dissolved in $0.12 \mathrm{mM} \mathrm{HCl}$ (contain $0.01 \%$ dimethylsulfoxide) at $1 \mathrm{~mm}$ and stored at $-20^{\circ} \mathrm{C}$. Epigallocatechin-3-gallate (EGCG) was used as a positive control. Antioxidants, such as EGCG, vitamin $\mathrm{C}$, and $\mathrm{E}$ inhibit the expression of MMP-1 in human skin fibroblasts. EGCG is a major constituent polyphenol in green tea and commonly used for preventing UV-induced adverse skin reaction such as sunburn and photoaging. ${ }^{20)}$

Primary Human Skin Fibroblast Cell Culture and Cell Proliferation Assay Primary human foreskin dermal fibroblasts were established by outgrowth from biopsies of healthy donors of 3-12 years and cultured in Dulbecco's modified Eagle's media (DMEM) supplemented with glutamine $(2 \mathrm{~mm})$, penicillin $(400 \mathrm{U} / \mathrm{ml})$, streptomycin $(50 \mathrm{mg} / \mathrm{l})$, and $10 \%$ fetal calf serum (FCS) in a humidified $5 \% \mathrm{CO}_{2}$ atmosphere at $37^{\circ} \mathrm{C}$. Cultured cells at passages $6-10$ were used for the experiments. The fibroblasts were cultured until $90 \%$ confluency and then, subcultivated. Cells cultured after 5 passages were used for the experiments. For treatment, primary human skin fibroblasts were maintained on culture media without FBS for $48 \mathrm{~h}$. Proliferation of cells was determined by the MTT assay, ${ }^{21)}$ which is based on the reduction of the soluble yellow MTT tetrazolium salt [3-(4,5-dimethylthiazol-2-yl)-2,5-diphenyl tetrazolium bromide] to its blue insoluble MTT formazan product by mitochondrial succinic dehydrogenase. After componds or UV treatment, the cells $\left(1 \times 10^{5}\right.$ cells/well $)$ were cultured for the indicated days. The cells were washed with PBS, $200 \mu \mathrm{l}$ of MTT $(0.05 \mathrm{mg} /$ $\mathrm{ml}$ ) was added to each well, and the cells were incubated for $4 \mathrm{~h}$ at $37^{\circ} \mathrm{C}$. The supernatant was then removed, and $200 \mu \mathrm{l}$ of dimethylsulfoxide was added to each well to dissolve the formazan product. Wells without cells were used as blanks. Absorbance was determined at $570 \mathrm{~nm}$, spectrophotometrically, using an ELISA reader (TECAN, Salzburg, Austria). The results were expressed as the percentage of control cells in eight same culture conditions.

Luciferase Assay for Human MMP-1 Inhibitor Analysis For human MMP-1 promoter analysis, NIH3T3 cells were plated into 6 -well plates at a density of $1 \times 10^{5} /$ well. NIH3T3 cells were transfected with promoter reporter gene construct, which contain a promoter fragment from 2278 to 34 nucleotides of 5 '-flankling sequence of the human MMP1 promoter and extending to +36 relative to the transcription start site, was constructed. ${ }^{23)} 24 \mathrm{~h}$ after incubated, the medium was changed for medium with or without 10 , $100 \mu \mathrm{g} / \mathrm{ml}$ sample, and cell lysates were collected for the luciferase assay from $24 \mathrm{~h}$ later. The luciferase activities of the cell lysates were measured according to the manufacturer's recommendations (Applied Biosystems)

UV Irradiation The UV light source was a $\mathrm{F} 75 / 85 \mathrm{~W} /$
UV21 fluorescent sun lamps, having an emission spectrum between $285-350 \mathrm{~nm}$ (peak at $310-315 \mathrm{~nm}$ ) as previously described. ${ }^{22)}$ A Kodacel filter (TA401/407; Kodak, Rochester, NY, U.S.A.) was mounted $2 \mathrm{~cm}$ in front of the UV tubes to remove wave lengths $<290 \mathrm{~nm}$ (UV-C). The fibroblasts were grown in $10 \mathrm{~cm}$ culture dishes (Falcon, Lincoln Park, NJ, U.S.A.) until subconfluent. Subsequently, the cells were cultured in serum-free medium for $24 \mathrm{~h}$, and the medium was replaced by $2 \mathrm{ml}$ of phosphate-buffered saline. Then the cells were exposed to UV $\left(0-100 \mathrm{~mJ} / \mathrm{cm}^{2}\right)$ light. After irradiation ( 1 min $20 \mathrm{~s}$ ), the cells were washed with phosphate-buffered saline, and $72 \mathrm{~h}$ cultured in the serum free media with or without compounds.

Western Blot Analysis and Statistical Analysis Supernatant extract were centrifuged at $12000 \times \boldsymbol{g}$ for $10 \mathrm{~min}$ at $4{ }^{\circ} \mathrm{C}$ and used for western blot analysis. A monoclonal antiMMP-1 antibody (Oncogen, Co., Boston, MA, U.S.A.) and monoclonal anti-type I procollagen aminoterminal extension peptide (SP1. D8) antibody (Developmental Studies Hybridoma Bank, Iowa City, IA, U.S.A.) were used as primary antibodies. Anti-mouse IgG-HRP conjugates was used as secondary antibodies. The antibody-antigen complexes were detected using the ECL system (Amersham Pharmacia Biotech; Little Chalfont, U.K.). To determine the amounts of MMP-1 (42/46 kDa) and type I procollagen (170-190 kDa) secreted into culture media, equal aliquots of conditioned culture media from an equal number cells were fractionated by $10 \%$ SDS-PAGE, transferred to Hybond ECL membrane. From membrane stain, validate of equal loading, Signal strengths were quantified using a densitometric program (TINA; Raytest Isotopenme gerate, Germany). Statistical significance was determined using the Student $t$-tests. Results are presented by means \pm S.E.M. All $p$ values quoted are twotailed and were accepted as significant when $p$ was $\leq 0.05$. The experiments were repeated at ten times per treatment $(n=10)$.

\section{RESULTS AND DISCUSSION}

The methylene chloride extract had a MMP-1 expression inhibition effect; the MMP-1 expression level decreased to $74.62 \%$ at $10 \mu \mathrm{g} / \mathrm{ml}$ and $53.23 \%$ at $100 \mu \mathrm{g} / \mathrm{ml}$ compared with the control by human MMP-1 promoter analysis, activityfraction column chromatographies of a methylene chloride soluble fraction from the stems of $S$. japonica led to the isolation of compounds (oleanolic aldehyde acetate (1), erythrodiol-3-acetate (2), euphorginol (3), anhydrosophoradiol-3-acetate (4); Fig. 1). Compounds 1 and 4 exhibited potent cytotoxicity against human dermal fibroblasts $\left(\mathrm{IC}_{50}: 0.84 \mu_{\mathrm{M}}(\mathbf{1})\right.$, and $1.12 \mu \mathrm{M}(4)$, respectively), and compounds 2,3 did not showed cytotoxicity against the human dermal fibroblasts in the test dose $(0.01-1) \mu \mathrm{M},{ }^{\#} p<0.05$ compared to the UV irradiated control) (Fig. 2). To examine the effects of compounds 2,3 on the expression of MMP-1 and type 1 procollagen in primary human skin fibroblasts, we exposed cultured human skin fibroblasts to $100 \mathrm{~mJ} / \mathrm{cm}^{2}$ using UV light, and measured the MMP-1 and type 1 procollagen levels at $72 \mathrm{~h}$ by western blot analysis. Human skin fibroblasts were treated with $0.01,0.1,1 \mu \mathrm{M}$ for $72 \mathrm{~h}$ and then, the expression levels of MMP-1 and type I procollagen were determined in the culture media by western blot analysis. We have investigated 


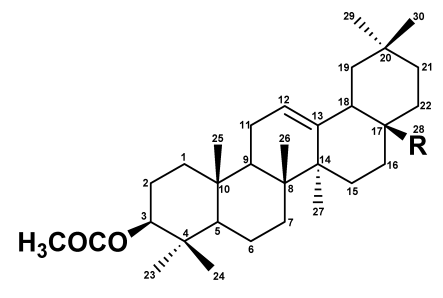

Oleanolic aldehyde acetate $(1): \mathbf{R}=\mathbf{C H O}$ Erythrodiol-3-acetate (2): $\mathrm{R}=\mathrm{CH}_{2} \mathrm{OH}$

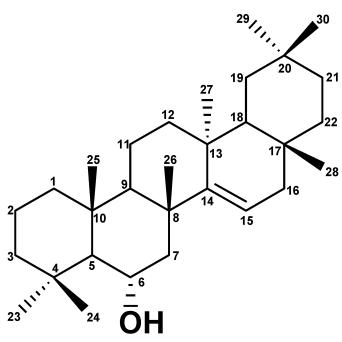

Euphorginol (3)<smiles>CC(=O)O[C@H]1CC[C@]2(C)[C@@H](CC=C3C4CC(C)(C)C=C[C@]4(C)CC[C@@]32C)C1(C)C</smiles>

Anhydrosophoradiol- 3-acetate (4)

Fig. 1. Chemical Structures of Compounds $\mathbf{1}-\mathbf{4}$ from Styrax japonica

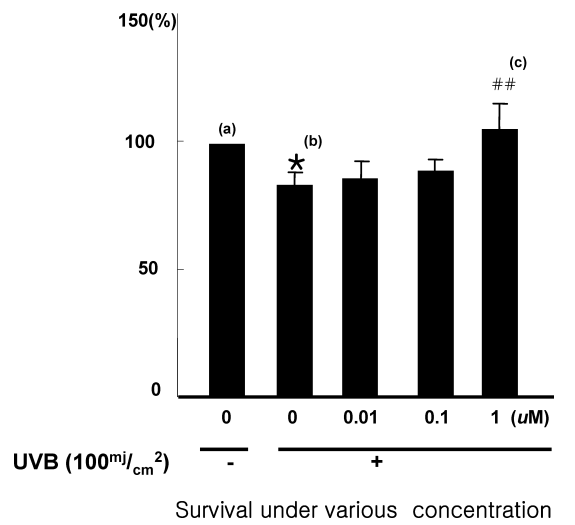

Fig. 2. The Effects of Erythrodiol-3-acetate (2) on the Cell Survival Caused by UV Irradiation in Cultured Primary Human Skin Fibroblasts

(a) As $100 \%$ control, non-treatment control was determined in the levels of the UV absorbance value using MTT assay. (b) Data are expressed as mean \pm S.E. $(n=10)$ $* p<0.05$ compared to the non UV irradiated control. (c) Data are expressed as mean \pm S.E. $(n=10) \# p<0.01$ compared to the UV irradiated control.

the effects of erythrodiol-3-acetate (2) and euphorginol (3) on the MMP-1 and type 1 procollagen synthesis in DMEM media using primary cultured human fibroblasts cause by UV irradiation. Erythrodiol-3-acetate showed equal activity to positive control (EGCG), but euphorginol did not showed activity. We demonstrated that erythrodiol-3-acetate decreased the expression of MMP-1 and increased the expression of type 1 procollagen at the protein levels in a dose-dependent manner cause by UV irradiation of cultured human skin fibroblasts. To investigate the dose-dependent effects of erythrodiol-3-acetate (2), human skin fibroblasts were treated with various doses of erythrodiol-3-acetate for $72 \mathrm{~h}$ cause by UV irradiation. The type I procollagen protein regulation increased by $121.1 \pm 12 \% \quad(p<0.05, n=10)$ at $0.01 \mu \mathrm{M}$, $175.4 \pm 11 \%(p<0.05, n=10)$ at $0.1 \mu \mathrm{M}$, and $223.7 \pm 12 \%$ $(p<0.05, n=10)$ at $1 \mu \mathrm{M}$ (Fig. 3) and erythrodiol-3-acetate treatment potential inhibited UV-induced MMP-1 protein

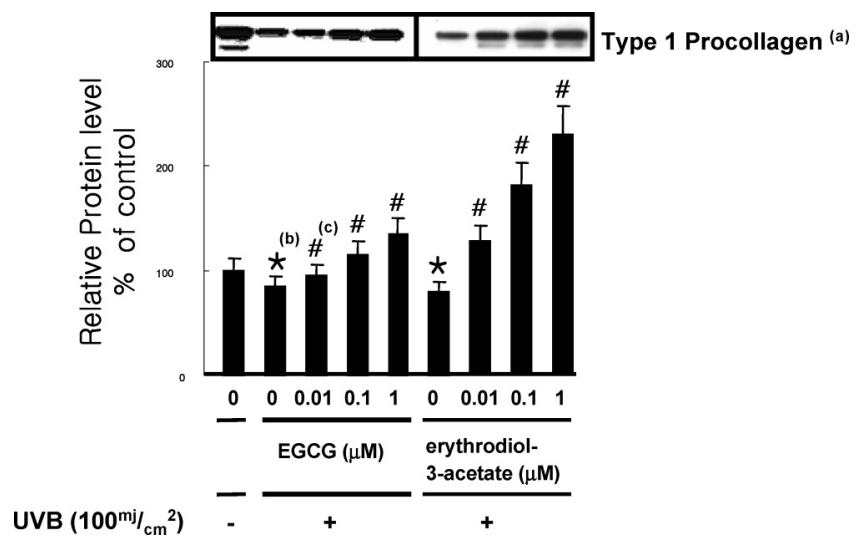

Fig. 3. The Effect of Erythrodiol-3-acetate (2) on the Product of Type I Procollagen Caused by UV Irradiation in Cultured Primary Human Skin Fibroblasts

Quiescent primary human skin fibroblasts were exposed to UV $100 \mathrm{~mJ} / \mathrm{cm}^{2}$ and collected at indicated time points. Conditioned media of fibroblasts at $72 \mathrm{~h}$ time point following exposure to UV-B light were collected and Western blotted with anti-type 1 procollagen antibody, and also subjected to Western blot for type 1 procollagen expression. Values represent the means \pm S.E. of data from ten independent experiments. (a) Erythrodiol-3-acetate induced the expression of Type I procollagen. (b) Data are expressed as mean \pm S.E. $(n=10) * p<0.05$ compared to the non UV irradiated control. (c) Data are expressed as mean \pm S.E. $(n=10) \# p<0.05$ compared to the UV irradiated control.

levels to the control levels in a dose-dependent manner by $73.1 \pm 10 \%(p<0.05, n=10)$ at $0.01 \mu \mathrm{M}, 62.3 \pm 13 \%(p<0.05$, $n=10)$ at $0.1 \mu \mathrm{M}$, and $53.2 \pm 11 \%(p<0.05, n=10)$ at $1 \mu \mathrm{M}$, compared with UV irradiated control (Fig. 4). We investigated the effects of MMP-1 and type 1 procollagen caused by UV irradiation in human primary skin fibroblasts. Therefore, the regulation of MMP activity might be a potential strategy for prevention and/or treatment of UV-induced skin damage. ${ }^{4)}$ In conclusion, erythrodiol-3-acetate may be used for the treatment and prevention of skin aging processes by UV irradiation.

Acknowledgements This study was supported by grant 


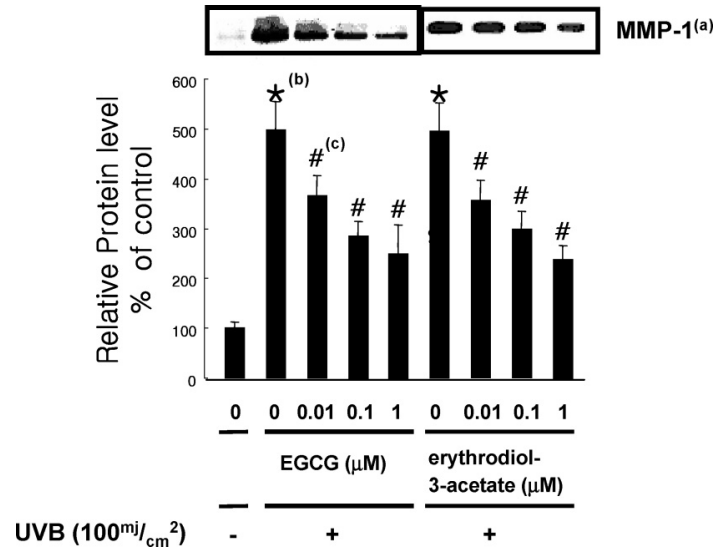

Fig. 4. The Effect of Erythrodiol-3-acetate (2) on the Product of MMP-1 Caused by UV Irradiation in Cultured Primary Human Skin Fibroblasts

Quiescent primary human skin fibroblasts were exposed to UV $100 \mathrm{~mJ} / \mathrm{cm}^{2}$ and collected at indicated time points. Conditioned media of fibroblasts at $72 \mathrm{~h}$ time point following exposure to UV-B light were collected and Western blotted with anti-MMP-1 antibody, and also subjected to Western blot for MMP-1 expression. Values represent the means \pm S.E. of data from ten independent experiments. (a) Erythrodiol-3-acetate reduced the expression of MMP-1. (b) Data are expressed as mean \pm S.E. $(n=10)$ $* p<0.05$ compared to the non UV irradiated control. (c) Data are expressed as mean \pm S.E. $(n=10) \# p<0.05$ compared to the UV irradiated control.

of the Korea Health 21 R\&D Project, Ministry of Health \& Welfare, Republic of Korea (03-PJ1-PG1-CH14-0001).

\section{REFERENCES}

1) Yaar M., Gilchrest B. A., J. Dermatol. Surg. Oncol., 16, 915-922 (1990).

2) Fisher G. J., Wang Z. Q., Datta S. C., Varani J., Kang S., Voorhees J. J., N. Engl. J. Med., 337, 1419-1428 (1997).

3) Varani J., Warner R. L., Gharaee-Kermani M., Phan S. H., Kang S.,
Chung J. H., Wang Z. Q., Datta S. C., Fisher G. J., Voorhees J. J., J. Invest. Dermatol., 114, 480-486 (2000).

4) Fisher G. J., Datta S. C., Talwar H. S., Wang Z. Q., Varani J., Kang S., Voorhees J. J., Nature (London), 379, 335-339 (1996).

5) Chung J. H., Seo J. Y., Choi H. R., Lee M. K., Youn C. S., Rhie G., Cho K. H., Kim K. H., Park K. C., Eun H. C., J. Invest. Dermatol., 117, 1218-1224 (2001).

6) Chung J. H., Seo J. Y., Lee M. K., Eun H. C., Lee J. H., Kang S., Fisher G. J., Voorhees J. J., J. Invest. Dermatol., 119, 507-512 (2002).

7) Visse R., Nagase H., Circ. Res., 92, 827-839 (2003).

8) Sternlicht M. D., Werb Z., Annu. Rev. Cell Dev. Biol., 17, 463-516 (2001).

9) Davis P. H., "Flora of Turkey and the East Aegean Islands," Vol. 4, University of Edinburgh Press, Edinburgh, 1972.

10) Costa A. F., "Farmacognosia," 2nd ed., Vol. 1, Fundação Calouste Gulbenkian, Lisboa, 1968, p. 737.

11) Vardar V., Oflas S., Plant Master Vrg., 22, 145-148 (1973).

12) Kircher H., Phytochemistry, 19, 2702-2712 (1980).

13) Akgul Y. Y., Anil H., Phytochemistry, 63, 939-943 (2003).

14) Anil H., Phytochemistry, 19, 2784-2786 (1980).

15) Kitagawa I., Imakura Y., Hayashi T., Yosioka I., Chem. Pharm. Bull., 23, 1520-1531(1975).

16) Nomura M., Tokoroyama T., Kubota T., Phytochemistry, 20, 1097 1104 (1981).

17) Rasool N., Khan A. Q., Malik A., Phytochemistry, 28, 1193-1195 (1989).

18) Kitagawa I., Wang H. K., Saito M., Yoshikawa M., Chem. Pharm. Bull., 31, 664-673 (1983).

19) Kim M. R., Lee H. H., Hahm K. S., Moon Y. H., Woo E. R., Arch. Pharm. Res., 27, 283-286 (2004).

20) Salah N., Miller N. J., Paganga G., Tijburg L., Bolwell G. P., RiceEvans C., Arch. Biochem. Biophys., 322, 339-346 (1995).

21) Mosmann T., J. Immunol. Methods, 65, 55-63 (1983).

22) Seo J. Y., Lee S. H., Youn C. S., Choi H. R., Rhie G. E., Cho K. H., Kim K. H., Park K. C., Eun H. C., Chung J. H., J. Invest. Dermatol., 116, 915-919 (2001).

23) Pierce P. A., Sandefur S., Doyle G. A. R., Welgus H. G., J. Clin. Invest., 97, 1890-1899 (1996). 